\title{
A FIRST GEOMETRY
}

By D. N. STRAKER, Senior Mathematics Master, Downsend School, Leatherhead.

A new geometry course in two parts which covers completely the syllabus for the Common Entrance examination to Public Schools. However, the course has been written with the needs and difficulties of all beginners in mind, and it would be suitable for the first two or three years of a secondary school course. It aims to introduce geometry to the beginner in a manner easy to understand, at the same time ensuring that he learns the correct way to set out a theoretical proof. Facts are discovered by a combination of drawing and measurement and simple deduction; later they are proved in theorem form. There are over 500 line figures in Parts One and Two.

"These are pleasing books, attractively printed and bound. Pupils will like them, and they will welcome the division into two parts which will give them a new book for their second year."-The Times Educational Supplement. Part I, 6s. Part 2, 6s. Answer Book, 2s. 6d.

\section{EXERCISES IN ELEMENTARY GEOMETRY}

By C. R. SPOONER, B.A. and P. W. STURGESS.

"The questions [over 1,600] are easy enough to encourage the most timid, numerous enough to give confidence to the slowest, yet sufficiently varied in range to extend the pacemakers." - The Times Educational Supplement.

With Answers, 8s. 6d. Without Answers, 7s. 6d.

\section{COUNTING AND ARITHMETIC IN THE INFANTS SCHOOL}

By W. G. BASS, B.SC., M.I.E.E. and O. S. DOWTY.

"The book under review is written, in collaboration with an infants' school headmistress, by a business man perturbed at the weakness in mathematics shown by his young apprentices and rightly convinced that all later work depends on the clear teaching of the fundamental steps. ... Some may feel that the method is too mechanical; many others will rejoice at its lucidity and simplicity." - The Times Educational Supplement. Illustrated.

7s. 6d.

\section{GEORGE G. HARRAP \& CO. LTD}

I82 High Holborn London W.C.I 


\section{A 5-YEAR SCHEME FOR THE ALTERNATIVE SYLLABUS Mathematics Today}

by E. E. Biggs and H. E. Vidal

\section{INTRODUCTORY COURSE}

\begin{tabular}{|c|c|c|c|}
\hline PART ONE & The Tools of Mathematics & 336 pages & 8 s. $9 \mathrm{~d}$. \\
\hline PART TWO & Mathematics in Action & 288 pages & 8s. $3 \mathrm{~d}$. \\
\hline \multicolumn{4}{|c|}{ MAIN COURSE } \\
\hline PART ONE & The World We Live In & 336 pages & \\
\hline PART TWO & The Measurement of the World & 368 pages & 10s. 0d. \\
\hline PART THREE & Largest and Smallest & 208 pages & $7 \mathrm{~s}$. \\
\hline
\end{tabular}

FROM A REVIEW IN A.M.A. 'Why have the proposals of the Jeffery Report [for an Alternative Syllabus] made so little headway? It is due, I think, to the lack, so far, of a really satisfying textbook based on its principles. . . Mathematics Today will, in my view, prove a first-class advertisement for the Alternative Syllabus. The whole book is the result of an experiment in a girls' large grammar school, and I have no hesitation, although not myself a convert to the Jeffery Report, in describing this book as brilliant; the authors have certainly matched up to the new challenge and demonstrated in convincing style that a unified course is possible.

As a book written by a former senior mathematics mistress, and a head mistress of a girls' grammar school, it will nevertheless come as something of a shock that a text book on mathematics can be written, not ostensibly or so blatantly for boys, as such textbooks usually are, but to maintain the interest of both boys and girls.

I think no higher tribute can be given to the whole of this book than to say that future experiments and successes in the ideas of a unified course might well stand or fall on the way this textbook is received and adapted in the schools.'

\section{CUT OUT AND SEND FOR LOAN COPIES NOW}

To: GINN AND COMPANY LTD., 18 Bedford Row, London, W.C.1

Please send me a loan copy of Mathematics Today

(Fill in what is wanted)

Name

School

M.G. 72 


\section{McGRAW-HILL}

\section{lan N. Sneddon \\ Elements of Partial \\ Differential Equations}

$56 \mathrm{~s} 6 \mathrm{~d}$

American Mathematical Society

Applied Probability about 26s 6d

American Mathematical Society Numerical Analysis

$73 \mathrm{~s}$

G. R. Stibitz and J. A. Larivee Mathematics and Computers $37 s 6 d$

H. M. Nodelman and F.W. Smith

Mathematics for

Electronics with Applications

$52 \mathrm{~s} 6 \mathrm{~d}$

Harry Lass

Elements of Pure and Applied Mathematics $56 \mathrm{~s} 6 \mathrm{~d}$

R. C. Buck Advanced Calculus $64 \mathrm{~s}$
A sound and interesting introduction for honours students of mathematics, physics, chemistry and engineering, and for graduate students in their first year of research work. The engineering applications of the equations are stressed. already published

Nine papers given at a symposium of the American Mathematical Society in April 1955 at Brooklyn Polytechnic Institute. They are concerned with diffusion theory, theory of turbulence and probability in classical and modern physics.

\section{May-June}

Over twenty eminent mathematicians contributed to the Sixth Symposium of the American Mathematical Society, held in 1953. The papers show clearly how far interest in numerical analysis has increased during the past ten years. already published

The aim of this important survey, based on lectures given to engineers at the University of California, Los Angeles, is to relate the rapid advances in mathem atical applied thought to engineering technology and design. already published

The problems and methods of the applied mathematician are studied in this new book, which examines the uses and limitations of computing devices for solving problems in business, industry, science and engineering. already published

In this new book, written especially for students of electronic and television engineering, the mathematical topics are closely related to actual electronic engineering problems. It will also be useful for practising engineers. already published

A comprehensive textbook for honours degree students, which will also be useful as a reference book for practising mathematicians, physicists and engineers. Vector and tensor analysis, statistics and probability theory are fully discussed. already published

First year honours students with a sound foundation in basic calculus and some knowledge of differential equations will find this book a good introduction to modern ideas in mathematics. The treatment is practical and up-to-date. already published 


\title{
MATHEMATICAL LOGIC
}

\section{by R. L. GOODSTEIN}

THE introduction of mathematical symbolism and techniques into formal logic has produced over the past hundred years a branch of mathematics unsurpassed by any in the power and originality of its results. This brief survey covers many facets of the subject and is designed to be read by mathematicians who have little or no previous knowledge of symbolic logic. The contents include sentence and predicate logic, class logic, and the foundations of arithmetic in different levels of logic; major results such as the relativity of class concepts, the completeness of predicate logic, and the incompleteness of, and decision problem for, arithmetic are proved in detail.

Demy 8vo. Cloth-bound. viii +104 pp. 21s. net.

\section{AXIOMATIC PROJECTIVE GEOMETRY}

\section{by R. L. GOODSTEIN and E. J. F. PRIMROSE}

'The authors have succeeded in their task of showing that the subject can be developed rigorously and elegantly, while keeping the arguments at an elementary level.' The Mathematical Gazette.

Demy 8vo. Cloth-bound. xi +140 pp. 15s. net.

\section{CONSTRUCTIVE FORMALISM}

\author{
by R. L. GOODSTEIN
}

'A valuable and stimulating contribution.' Mathematical Reviews.

Demy 8vo. Paper-covered. 91 pp. 15s. net

\section{THE FOUNDATIONS OF MATHEMATICS}

\author{
by R. L. GOODSTEIN
}

'A brief summary, intended for the general reader, of work on the foundations of mathematics from Euclid to the present day.' Zentralblatt fur Mathematik.

Crown 8vo. Paper-covered. 1s. net

\section{LEICESTER UNIVERSITY PRESS}




\section{MUCHA МICS}

By H. Weiler, Lic.ès.Sc. (Paris), etc. Covers all the subject-matter for the Advanced Level, Scholarship and Intermediate Examinations in Applied Mathematics. The author has paid much attention to the logical development of the subject and text is sufficiently detailed for it to be read with ease without the assistance of a teacher. A knowledge of Calculus, but none of the differential equations, is needed and in the introductory chapters proofs are derived from first principles. Pitman's Intermediate Science Series. 25:-

\section{MA THEMA THCS}

By A. T. Starr, M.A., Ph.D., M.I.E.E. This book has been written specially to cover the syllabus of Mathematics Parts I and $\mathbf{2}$ for the degree in Engineering of the University of London. It covers also the syllabuses of the Ordinary and Higher National Certificates. Many examples are worked out in the fields of Physics and Electrical Engineering and many exercises are included. An elementary treatment of Operational Calculus is given by the method of the Laplace Transform in order that the student may be able to take advantage of the modern work which prefers this method. Pitman's Engineering Degree Series. 45/-net.

\section{PITIIAN technical books}

Parker St., Kingsway, London, WC2

\section{SUMMER SCHOOL IN MATHEMATICS AND PHYSICS}

UNIVERSITY OF ST. ANDREWS

A summer school for school teachers of science and mathematics, to help them keep in touch with scientific developments, both in teaching and research will be held in St. Andrews from 3 rd to Ioth August 1957. The fee for the course will be $£ 3$ os. od. of which $10 /-$ is payable on enrolment. The cost of accommodation is $\AA^{6}$ i5s. 6d. Further particulars may be obtained from Dr. D. E. Rutherford, St. Salvator's College, St. Andrews. 


\title{
The Hypercircle in Mathematical Physics
}

J. L. SYNGE

In electrostatics, hydrodynamics and elasticity, the physicist or engineer often has to solve partial differential equations subject to boundary conditions. In this book Professor Synge sets out a method for the approximate solution of boundary value problems. Early Summer. About 90s. net

\section{Introduction to \\ Diophantine Approximation}

\author{
J. W. S. CASSELS
}

This forty-fifth volume in the series of CAMBRIDGE MATHEMATICAL TRACTS is an introduction to the basic results and techniques in the theory of Diophantine Approximation, a branch of Number Theory. Much of the book deals with developments since 1936, and there is a useful select bibliography.

Early Summer

About 25s. net

\section{The Teaching of Mathematics}

A report issued by the Incorporated Association of Assistant Masters in secondary schools, principally on secondary grammar school work. The topics discussed include: What is Mathematics?; The influence of psychology; Nunn's principles; Mathematics as mental training; Immediate ends; Ultimate ends; Syllabuses, traditional and alternative.

Ready Summer

About 25s.

\section{CAMBRIDGE UNIVERSITY PRESS}

BENTLEY HOUSE, 200 EUSTON ROAD, LONDON, NW.I 


\section{PART IV \\ OF}

ELEMENTARY MATHEMATICS

by

C. G. NOBBS

is now published

Pp. 384 including Answers. 12s. 6d.

' There are several notable departures from normal practice in this. ... The most significant of these is the sub-division of the contents into 130 sections or topics with a continuity which gives satisfactory coherence in the treatment of the subject as a whole. ... The text contains apt references to the history of mathematics. There is an abundance of exercises and the worked examples are so presented as to have good teaching value. The suggestions for practical work and the nature of many of the problems will please those who believe that mathematics need be neither dull nor dissociated from the interests of children. This promises to be a first-rate series.'

The Times Educational Supplement reviewing Part I

'... The bookwork is very sound and easy to follow, and the numerous well chosen exercises will suit the ability of any student.'

The Technical Journal reviewing Part II

A detailed prospectus is available.

\section{OX F OR D U N I VERSITY PRES S EDUCATION DEPARTMENT OXFORD}

